\title{
Isolation of a Gene Required for Growth of Escherichia coli on Fumarate and $\mathrm{H}_{2}$
}

\author{
By ALPANA CHAUDHURI AND ALVIN I. KRASNA* \\ Department of Biochemistry and Molecular Biophysics, The Cancer Center/Institute for \\ Cancer Research, College of Physicians and Surgeons, Columbia University, New York, \\ New York 10032, USA
}

(Received 30 December 1987; revised 18 April 1988)

\begin{abstract}
Two mutant strains of Escherichia coli, AK11 and AK22, express normal levels of hydrogenase activity, assayed by deuterium exchange, when grown on glucose or complex medium but cannot reduce methyl viologen by $\mathrm{H}_{2}$ nor grow on fumarate plus $\mathrm{H}_{2}$. The mutant strains also lack formate hydrogenlyase and formate dehydrogenase activities. The mutation in these strains was located near minute 17 of the genome map and a single mutation was shown to be responsible for loss of both hydrogen uptake and formate-related activities. Membrane vesicles and solubilized membranes of strains AK 11 and AK22 were capable of methyl viologen reduction by $\mathrm{H}_{2}$ and had the normal complement of hydrogenase isoenzymes 1 and 2 . Intact cells of the mutant strains could reduce fumarate by $\mathrm{H}_{2}$ but could not grow under these conditions. A plasmid, pAK 11, was isolated, as well as smaller plasmids derived from it, which restored the hydrogen uptake activities in the two mutant strains, the smallest active DNA fragment being $1.4 \mathrm{~kb}$. The formate activities were partially restored by some of the plasmids. The plasmids which restored hydrogen uptake activities led to synthesis of a polypeptide of subunit molecular mass $30 \mathrm{kDa}$.
\end{abstract}

\section{INTRODUCTION}

Anaerobic growth of Escherichia coli cells on glucose, in the absence of added electron acceptors, leads to $\mathrm{H}_{2}$ production. Glucose is degraded via pyruvate to acetate and formate, and the latter is then cleaved to $\mathrm{CO}_{2}$ and $\mathrm{H}_{2}$ by 'formate hydrogenlyase', composed of formate dehydrogenase and hydrogenase. Cells can grow on glucose even in the absence of hydrogenase or when hydrogenase activity is inhibited (Krasna, 1980, 1984). Maximal levels of hydrogenase activity are expressed when hydrogenase is essential for anaerobic growth, and such growth ceases when hydrogenase is inhibited (Krasna, 1980, 1984). These conditions are achieved when cells are grown on fumarate as the sole carbon source in the presence of $\mathrm{H}_{2}$ gas. In this case, $\mathrm{H}_{2}$ is used as electron donor and fumarate, the electron acceptor, is reduced to succinate (Macy et al., 1976; Yamamoto \& Ishimoto, 1978) in a pathway which generates ATP by oxidative phosphorylation. This pathway is dependent on fumarate reductase as well as electron carriers which couple this enzyme to $\mathrm{H}_{2}$ as electron donor (Cole et al., 1985; Lambden \& Guest, 1976; Spencer \& Guest, 1973). There are three distinct hydrogenase isoenzymes in $E$. coli required for $\mathrm{H}_{2}$ evolution and uptake under different conditions of growth (Sawers et al., 1985).

The reduction of fumarate can also be coupled to the oxidation of glycerol-3-phosphate, $\mathrm{NADH}$, lactate, formate and dihydroorotate, with a specific enzyme being required for each substrate (Cole et al., 1985). This occurs via a membrane-linked electron-transport chain composed of a $b$-type cytochrome, a lipid-soluble quinone, fumarate reductase, and perhaps electron carriers specific for each oxidizable substrate. Mutations in any of the components of the pathway would inhibit growth on the specific substrate and fumarate.

Abbreviations: FDH-1, formate dehydrogenase 1; FDH-2, formate dehydrogenase 2; FHL, formate hydrogenlyase. 
E. coli strains with mutations leading to the loss of all hydrogenase activity (genotype hyd) fail to grow on fumarate plus $\mathrm{H}_{2}$ (Krasna, 1984; Lee et al., 1985; Sankar et al., 1985; Chaudhuri \& Krasna, 1987) but grow on glycerol plus fumarate, indicating the presence of active fumarate reductase. This laboratory (Krasna, 1984) has isolated two mutant strains of $E$. coli (AK11 and AK22) which show a hydrogen-uptake-negative phenotype, Hup- (failure to reduce methyl viologen with $\mathrm{H}_{2}$ and failure to grow on $\mathrm{H}_{2}$ plus fumarate), but express normal levels of hydrogenase, as measured by the deuterium exchange assay, when grown anaerobically on glucose or complex medium (genotype hup). These mutant strains grow on glycerol plus fumarate. The unique characteristic of these strains is that the hydrogenase activity is only detected in intact cells by the exchange assay.

Failure to grow on fumarate plus $\mathrm{H}_{2}$, in the presence of fumarate reductase and hydrogenase, could be due to a number of possible mutations in the $\mathrm{H}_{2}$-fumarate pathway. Lee et al. (1985) isolated mutant strains of $E$. coli (called class I hup mutants) with a Hup phenotype similar to strains AK 11 and AK22. The class I hup mutant strains mapped near minute 65 of the E. coli genome map.

This report describes a DNA fragment isolated from wild-type $E$. coli cells which restores the normal hydrogen uptake phenotype to mutant strains AK11 and AK22. The genotypic and phenotypic characteristics of the mutation are defined.

\section{METHODS}

Organisms and growth conditions. The wild-type strain used in this investigation was $E$. coli $\mathrm{K} 12 \mathrm{~W} 6$ met bio (ATCC 25019); the two mutant strains AK11 and AK22 were derived from this strain by mutagenesis with ultraviolet light and $N$-methyl- $N^{\prime}$-nitro- $N$-nitrosoguanidine, respectively (Krasna, 1984). E. coli strains MV10 trp $E$ and N99 galK were obtained from Drs D. Figurski and M. Goftesman of the Department of Microbiology, Columbia University, and were used as recipients for P1 c100 transduction.

Bacteria were grown in complex or minimal medium, the composition of which was given by Chaudhuri $\&$ Krasna (1987). The complex medium was supplemented with glucose $(0.5 \%)$ or formate $(0.2 \%)$ and the minimal medium contained glucose $(27 \mathrm{mM})$ or fumarate $(43 \mathrm{mM})$ as sole carbon source. Where appropriate, ampicillin or tetracycline was added to a final concentration of $60 \mu \mathrm{g} \mathrm{m}^{-1}$ or $15 \mu \mathrm{g} \mathrm{m} \mathrm{m}^{-1}$, respectively. For enzyme assays, cells were grown anaerobically in completely filled bottles. Growth on fumarate plus $\mathrm{H}_{2}$ was achieved by bubbling $\mathrm{H}_{2}$ into the growth medium. Protein was determined by the Lowry method.

Enzyme assays. The enzyme activities of interest (see below) were measured at $25^{\circ} \mathrm{C}$ in washed cell suspensions, crude extracts, membrane vesicles and solubilized membranes. Washed cells were suspended in 75 mM-sodium phosphate buffer, pH 6.7, and broken by ultrasonic treatment for $3 \mathrm{~min}$. Crude extracts were prepared by centrifugation at $13000 \mathrm{~g}$. The membrane fraction was prepared by centrifugation of the crude extracts at $130000 \mathrm{~g}$ and the membranes in the pellet were solubilized as described by Ballantine \& Boxer (1985).

Hydrogenase (EC 1.12.1.2) was assayed by the deuterium exchange method (Krasna, 1978) in $10 \%{ }^{2} \mathrm{H}_{2} \mathrm{O}$. One unit of activity is defined as the appearance of $0.1 \%{ }^{2} \mathrm{H}^{1} \mathrm{H} \mathrm{h} \mathrm{h}^{-1}$ in the gas phase, which is equivalent to reaction with $0.287 \mu \mathrm{mol} \mathrm{H}_{2} \mathrm{~min}^{-1}$. Methyl viologen reduction by $\mathrm{H}_{2}$ was measured spectrophotometrically at $600 \mathrm{~nm}$ in the presence of small quantities of sodium dithionite to maintain anaerobiosis. The assay mixture contained cells, membrane vesicles or solubilized membranes, and methyl viologen (10 mM), in 0.33 $\mathrm{M}$-phosphate buffer, pH 6.7. The mixture was gassed with $\mathrm{H}_{2}$ and the reaction started by addition of sodium dithionite to raise the absorbance at $600 \mathrm{~nm}$ to 0.2 and the increase in absorbance was then measured. A unit of activity is defined as the $\mathrm{H}_{2}-$ catalysed reduction of $1 \mathrm{nmol}$ methyl viologen $\min ^{-1}$. Formate dehydrogenase 1 (FDH-1; EC 1.2.2.3), formate dehydrogenase 2 (FDH-2; EC 1.2.1.2) and 'formate hydrogenlyase' (FHL, comprising hydrogenase and FDH-2) were assayed as previously described (Chaudhuri \& Krasna, 1987), one unit of activity in all cases being defined as the oxidation of $1 \mathrm{nmol}$ formate $\mathrm{min}^{-1}$. Reduction of fumarate $\left(17 \mathrm{mM}\right.$ ) by $\mathrm{H}_{2}$ was measured manometrically, one unit of activity being the uptake of $1 \mathrm{nmol} \mathrm{H}_{2} \mathrm{~min}^{-1}$.

Native gel electrophoresis. Polyacrylamide electrophoresis was done on solubilized membranes with a $6 \cdot 5 \%(w / v)$ separating gel and a $3 \%(\mathrm{w} / \mathrm{v})$ stacking gel (Ballantine \& Boxer, 1985) at pH 9.5 and 8.0 (Maurer, 1971). The pH 9.5 system maintained stacking at $\mathrm{pH} 8.3$ and separation at $\mathrm{pH} 9.5$ with a Tris/glycine running buffer at $\mathrm{pH} 8 \cdot 3$. The pH 8.0 system maintained stacking at $\mathrm{pH} 7.0$ and separation at $\mathrm{pH} \mathrm{8.0} \mathrm{with} \mathrm{a} \mathrm{Tris/barbital} \mathrm{running} \mathrm{buffer} \mathrm{at}$ $\mathrm{pH} 7.0$. The gels were placed in $100 \mathrm{~mm}$-sodium phosphate buffer, $\mathrm{pH} \mathrm{6.7,} \mathrm{containing} 1 \mathrm{~mm}$-methyl viologen and 1 mM-2,3,5-triphenyltetrazolium chloride and placed in a $\mathrm{H}_{2}$ atmosphere overnight. Hydrogenase activity was revealed as intense red zones.

Genetic techniques. Genetic mapping was done by hybridizing cloned DNA fragments to a NotI macrorestriction digest of $E$. coli DNA separated by pulsed-field gel electrophoresis as described by Smith et al. (1987). 
We are indebted to Dr C. L. Smith of the Department of Genetics and Development, Columbia University, for these hybridization studies. Fine mapping was carried out by P1 transduction (Miller, 1972). Transposon Tn10 was introduced into strain AK 11 by generalized transduction with bacteriophage P1 $c 100$. The P1 c100 lysate was prepared from $E$. coli strain MC4100 (F- araD139 $\Delta$ lacU169 rpsL150 relA1 flbB5301 thi ptsF25 deoC1 rbsR) containing random TnIO insertions (provided by Dr H. Shuman of the Department of Microbiology, Columbia University). Tetracycline-resistant transductants of the recipient strains were plated on selective media plus tetracycline $\left(20 \mu \mathrm{g} \mathrm{ml}^{-1}\right)$ and screened for the genetic marker of interest.

Screening methods for hydrogenase. The symbols Hup ${ }^{-}$and hup (hydrogen uptake) designate the phenotype and genotype of cells which have hydrogenase activity when assayed by the exchange reaction but do not reduce viologen dyes by $\mathrm{H}_{2}$ nor grow on fumarate plus $\mathrm{H}_{2}$. The symbols $\mathrm{Hyd}^{-}$and hyd designate the phenotype and genotype of cells that lack all demonstrable hydrogenase activity: exchange reaction, reduction of viologen dyes by $\mathrm{H}_{2}$, and growth on fumarate plus $\mathrm{H}_{2}$ (Krasna, 1984; Lee et al., 1985). The details of the screening methods were described by Chaudhuri \& Krasna (1987). Strains AK11 and AK22 are Hup- by these screening methods and when the mutation is complemented by a cloned DNA fragment they show the Hup ${ }^{+}$phenotype. To prove the complementation, the transformed cells are then grown on fumarate plus $\mathrm{H}_{2}$ and show high levels of hydrogenase activity by the deuterium exchange assay.

$C l o n i n g$ the gene which restores activity. The $E$. coli chromosomal DNA library prepared from strain K12W6 was described by Chaudhuri \& Krasna (1987). This recombinant plasmid library was prepared by ligating plasmid pBR322 treated with BamHI to chromosomal DNA partially digested with Sau3A. This DNA library was used to transform strains AK11 and AK22 with good efficiencies. A large number (about 40000) of Ap ${ }^{R}$ colonies were grown in fumarate plus $\mathrm{H}_{2}$ to enrich for $\mathrm{Hup}^{+}$cells (Chaudhuri \& $\mathrm{Krasna}$, 1987). These cells were then plated on agar and further tested for the Hup phenotype.

None of the transformants from strain AK22 were Hup ${ }^{+}$. From the transformation of strain AK11, a large number of $\mathrm{Hup}^{+}$colonies were detected. Fifteen separate isolates were then selected for further study. Plasmid DNA was prepared from each isolate and used to transform strain AK11 to the Hup ${ }^{+}$phenotype. In each case, all $\mathrm{Ap}^{\mathrm{R}}$ transformants were $\mathrm{Hup}^{+}$by all criteria, including high levels of deuterium exchange in cells grown on fumarate plus $\mathrm{H}_{2}$. The separate plasmids were mapped by restriction enzyme digestion and found to be identical; the plasmid was designated as pAK11.

Synthesis of plasmid-coded proteins. The maxicell procedure of Sancar et al. (1979) was followed except that a mixture of ${ }^{14} \mathrm{C}$-labelled amino acids was used in place of labelled methionine. E. coli strain CSR603 (Sancar et al., 1979) was obtained from the $E$. coli Genetic Stock Center, Yale University.

\section{RESULTS AND DISCUSSION}

\section{Restoration of the Hup ${ }^{+}$phenotype in strain AK11 by cloned DNA fragments}

E. coli mutant strains AK 11 and AK22 (Krasna, 1984) are not hydrogenase-negative since when grown anaerobically on glucose they have the same hydrogenase activity, as measured by deuterium exchange, as the wild-type parent, strain K12W6. They are Hup ${ }^{-}$when screened for reduction of viologen dyes and cannot grow on fumarate plus $\mathrm{H}_{2}$, although they grow on glycerol plus fumarate. None of the plasmids described previously (Sankar et al., 1985; Chaudhuri \& Krasna, 1987), which restored activity in hydrogenase-negative strains with mutations in hydA, hydB and hydE, restored activity in strains AK 11 and AK22. A plasmid, pAK 11 (10.9 kb, with a $6.5 \mathrm{~kb}$ chromosomal DNA insert), was isolated from strain AK11 transformed by an $E$. coli DNA library which restored the Hup ${ }^{+}$phenotype in strain AK 11 . This plasmid also restored the hydrogen uptake activities in strain AK22, suggesting that the mutations in the two strains are close to each other, if not in the same gene. This plasmid did not complement hydA, hydB or hydE mutations.

Table 1 reports the hydrogenase activity, as measured by deuterium exchange, for strain AK 11 transformed by pAK11. There was little change in this activity in cells grown anaerobically on glucose, but the transformants grew on fumarate plus $\mathrm{H}_{2}$ and expressed high levels of hydrogenase activity. Thus, the cloned DNA fragment restores the ability of the cells to grow on fumarate plus $\mathrm{H}_{2}$ as well as the ability to reduce viologen dyes by $\mathrm{H}_{2}$ (see below, Table 3 ). The restriction digest map of pAK 11 is shown in Fig. 1. The insert contains single cleavage sites for EcoRV, HindIII, and BalI, three sites for EcoRI, and four sites for PvuII. pAK11 was treated with these enzymes to give smaller fragments containing different parts of the insert DNA fragment and these were used to transform strain AK11. The results are summarized in Fig. 1 and Table 1. 


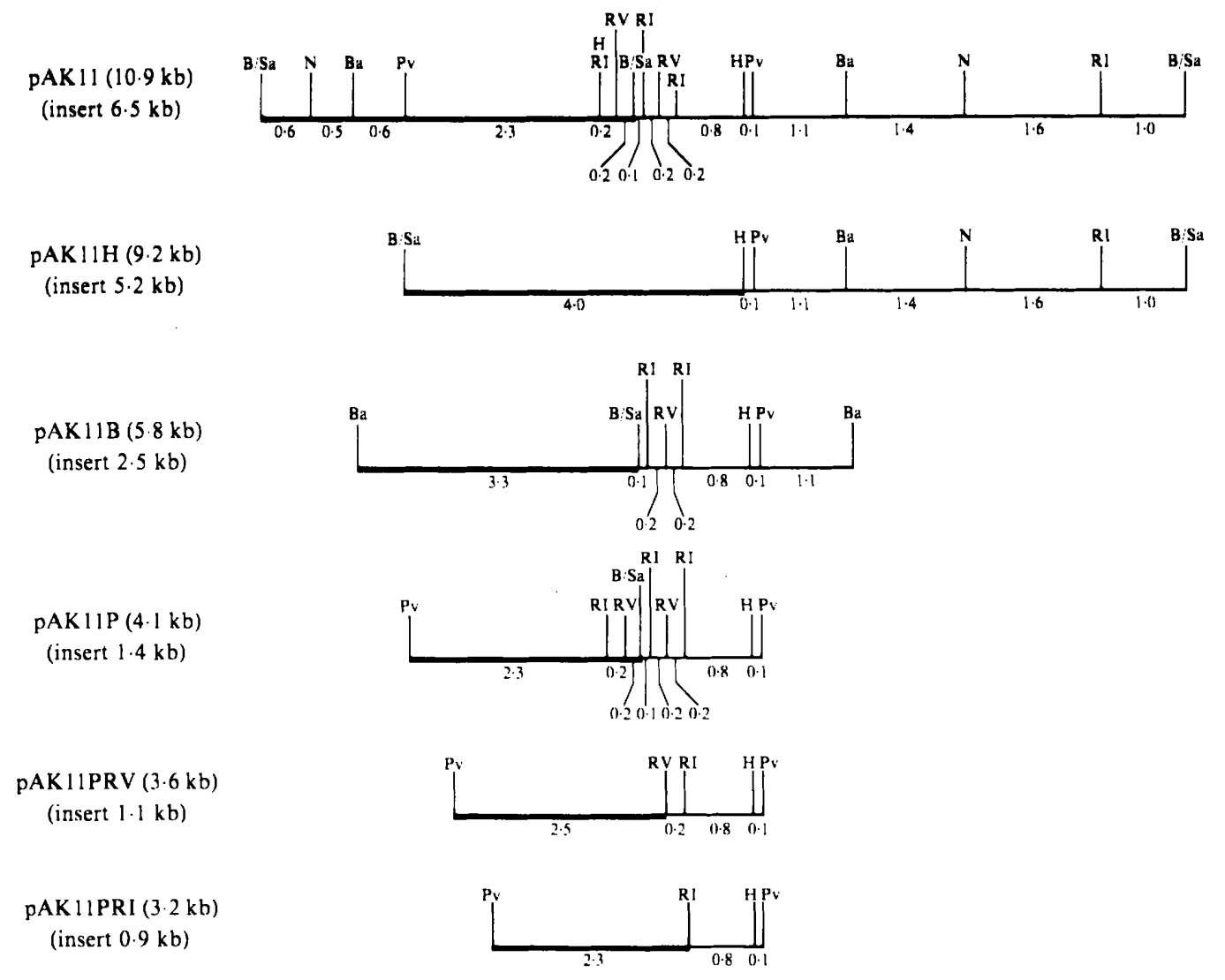

Fig. 1. Restriction digest maps of plasmids studied in strain AK11. The circular plasmids are written in linear form for ease of comparison. The heavy line is the vector plasmid and the light line is the chromosomal DNA insert. The numbers beneath the line indicate the size, in $\mathrm{kb}$, of the fragment between the two indicated restriction sites. The letters indicate the restriction sites and the abbreviations are: B/Sa, BamHI-Sau3A junction of vector and insert; Ba, BalI ; H, HindIII; N, NruI ; Pv, PvuII; RI, EcoRI; RV, EcoRV. There are additional sites in pAK 11 for NruI and PvuII to the right of the indicated sites. There is an additional EcoRI site in the insert fragment between the two sites indicated.

Plasmid pAK $11 \mathrm{H}$ did not restore the Hup ${ }^{+}$phenotype in strain AK11, suggesting that the $1.3 \mathrm{~kb}$ insert fragment to the left of the HindIII site in pAK 11 is required for activity. pAK $11 \mathrm{~B}$ (Fig. 1), with an insert of $2.5 \mathrm{~kb}$, was as active as pAK11 (Table 1). pAK11P, with a chromosomal DNA insert of $1.4 \mathrm{~kb}$, also restored the Hup ${ }^{+}$phenotype. pAK $11 \mathrm{P}$ was then digested with EcoRV or EcoRI to give the smaller plasmids pAK11PRV and pAK11PRI (Fig. 1). Both were inactive, suggesting that the $0.3 \mathrm{~kb}$ fragment at the extreme left (as drawn) of the $1.4 \mathrm{~kb}$ insert in pAK $11 \mathrm{P}$ is essential for activity. Similar results to those reported in Table 1 were obtained with mutant strain AK22.

Lee et al. (1985) isolated mutant strains of E. coli (called class I hup mutants) which mapped near minute 65 of the $E$. coli genome map and had a Hup phenotype similar to strains AK 11 and AK22. One strain of this clasś, strain SE-29 (a Tet ${ }^{\mathrm{S}}$ derivative of strain SE-8, kindly provided by Dr K. T. Shanmugam), was transformed by plasmids pAK11, pAK11B and pAK11P. None of these plasmids complemented the mutation in strain SE-29, suggesting that the mutation in that strain is different from the mutation(s) in strains AK11 and AK22. This conclusion will be confirmed by experiments reported below. 
Table 1. Hydrogenase exchange and formate-related activities of E. coli strain AKII transformed by plasmids

\begin{tabular}{|c|c|c|c|c|c|c|}
\hline \multirow[b]{2}{*}{$\begin{array}{l}\text { Recipient } \\
\text { strain }\end{array}$} & \multirow[b]{2}{*}{ Plasmid } & \multicolumn{2}{|c|}{$\begin{array}{l}\text { Exchange specific activity* } \\
\text { [units (mg protein) }{ }^{-1} \text { ] }\end{array}$} & \multicolumn{3}{|c|}{$\begin{array}{c}\text { Formate activities } \dagger \\
\text { [nmol formate oxidized } \min ^{-1} \\
\left.(\mathrm{mg} \text { protein })^{-1}\right]\end{array}$} \\
\hline & & $\begin{array}{l}\text { Glucose } \\
\text { grown }\end{array}$ & $\underset{\text { grown }}{\text { Fumarate }}+\mathrm{H}_{2}$ & $\widetilde{F H L}$ & FDH-2 & FDH-1 \\
\hline K 12W6 & None & 0.6 & $1 \cdot 3$ & 55 & 87 & 67 \\
\hline AK 11 & None & 0.6 & NG & 0 & 8 & 3 \\
\hline AK 11 & pAK 11 & 0.6 & $2 \cdot 0$ & 12 & 9 & 7 \\
\hline AK 11 & pAK $11 \mathrm{H}$ & ND & NG & ND & ND & ND \\
\hline AK 11 & pAK $11 \mathrm{~B}$ & 0.8 & $3 \cdot 1$ & 15 & 27 & 8 \\
\hline AK 11 & pAK $11 \mathrm{P}$ & 0.9 & 2.7 & 3 & 0 & 5 \\
\hline
\end{tabular}

Growth in high concentrations of $\mathrm{NiCl}_{2}$, which restores hydrogenase activity to hydE mutant strains of E. coli (Waugh \& Boxer, 1986; Chaudhuri \& Krasna, 1987) did not change the Hup phenotype of strains AK 11 and AK22.

\section{Formate-related activities of strain AK11 transformed by plasmids}

Mutant strain AK11 was assayed for $\mathrm{H}_{2}$ evolution from formate (FHL) and for two formate dehydrogenase activities, FDH-2 (benzyl-viologen-linked activity; the FDH associated with FHL) and FDH-1 (the FDH associated with nitrate reduction; Ingledew \& Poole, 1984). The results summarized in Table 1 show that the mutant strain is devoid of these activities even though it has normal hydrogenase activity as measured by deuterium exchange. The class I hup mutant strains isolated by Lee et al. (1985) were reported to have normal FHL and FDH activities and are, therefore, different from mutant strain AK 11.

Plasmid pAK 11, which restored growth on fumarate plus $\mathrm{H}_{2}$ and reduction of methyl viologen, restored only $22 \%$ FHL activity and no FDH-2 activity in strain AK 11 (Table 1 ). pAK 11 B restored $27 \%$ and $22 \%$ of the FHL and FDH-2 activities, respectively. pAK $11 \mathrm{P}$ failed to restore FHL or FDH-2 activities. None of the plasmids restored FDH-1 activity. Similar results to those reported in Table 1 were obtained with mutant strain AK22. Thus, although the three plasmids pAK $11, \mathrm{pAK} 11 \mathrm{~B}$ and $\mathrm{pAK} 11 \mathrm{P}$ restore the $\mathrm{Hup}^{+}$phenotype completely in strains AK 11 and AK22, they vary in their ability to restore the formate activities. A similar observation of variable ability of different plasmids to restore formate-related activities in a hydE mutant of $E$. coli (though they all restored hydrogenase activity) has been previously reported (Chaudhuri \& Krasna, 1987).

\section{Synthesis of plasmid-coded proteins}

The size and number of polypeptides synthesized by the pAK 11 plasmids was determined by the maxicell procedure of Sancar et al. (1979) (Fig. 2). The plasmid vector pBR322 coded for three polypeptides of molecular masses 43,33 and $28 \mathrm{kDa}$, which correspond to the three proteins reported to be encoded by this plasmid (Sancar et al., 1979). The 33 and $28 \mathrm{kDa}$ polypeptides are products of the $a m p$ gene and the $43 \mathrm{kDa}$ polypeptide is the product of the tet gene. Plasmids pAK11, pAK11B and pAK11P, all of which restored the hydrogen uptake activities in strains AK 11 and AK22, led to the synthesis of a new polypeptide of molecular mass $30 \mathrm{kDa}$. This polypeptide is readily distinguishable from the $28 \mathrm{kDa}$ polypeptide synthesized by the plasmid vector because it is observable after very short autoradiography whereas the $28 \mathrm{kDa}$ 
A

B

$\mathrm{C}$

D

$\mathrm{E}$

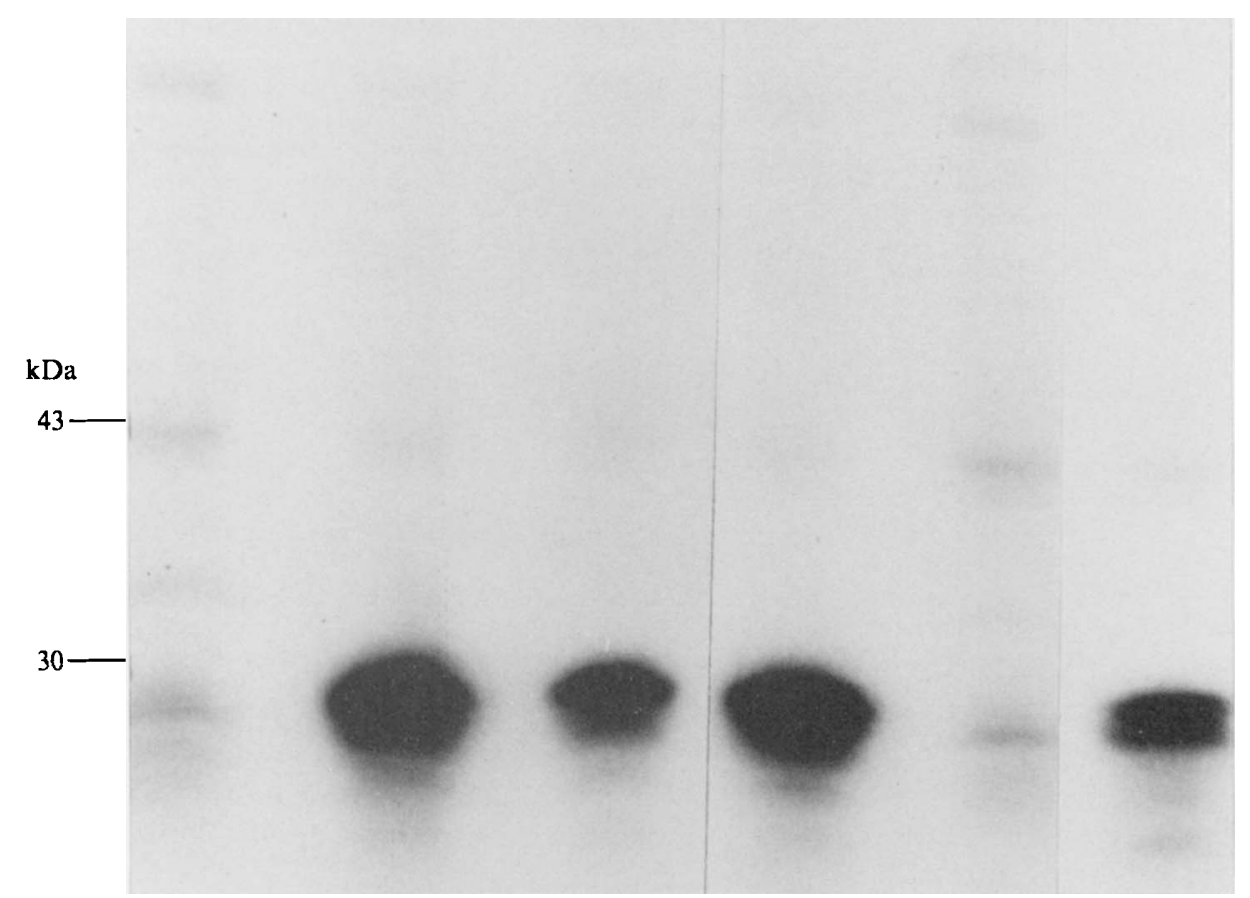

Fig. 2. Autoradiograph of an SDS-polyacrylamide gel of polypeptides expressed in maxicells ( $E$. coli CSR603) by pAK11-derived plasmids: A, pBR322; B, pAK11; C, pAK11B; D, pAK11P; E, pAK11H; F, pAK11PRV.

polypeptide is not. This polypeptide was not observed with pAK $11 \mathrm{H}$, which did not restore the $\mathrm{Hup}^{+}$phenotype. pAK11PRV, while inactive in restoring the $\mathrm{Hup}^{+}$phenotype, led to the synthesis of the $30 \mathrm{kDa}$ polypeptide, but at a much reduced level compared to the other plasmids. Thus the gene product which restores hydrogen uptake activities in strains AK 11 and AK22 may be a protein with subunits of molecular mass $30 \mathrm{kDa}$. The molecular mass reported may not be the actual size of the subunit. The protein band observed could be a hybrid protein created by fusion of the insert and plasmid DNA.

\section{Mapping the mutation in strain AKII}

To confirm that the mutation in strain AK 11 was different from the class I hup mutant strains described by Lee et al. (1985), it was necessary to map the mutation. Since a cloned DNA fragment which restores the Hup ${ }^{+}$phenotype to the mutant strain was available, the mutation could be mapped by hybridization of the cloned DNA to a macro-restriction map of the entire genome of $E$. coli. Smith et al. (1987) have prepared such a map by NotI macro-restriction digestion of $E$. coli DNA and size separation of the resulting DNA fragments by pulsed-field gel electrophoresis followed by hybridization to cloned DNA fragments of known genetic locations.

Plasmid pAK 11 was hybridized to a separated NotI digest of $E$. coli DNA and did not bind to band $A(1000 \mathrm{~kb})$, which represents minutes $58-82$ of the $E$. coli genome map. As a control, plasmid pAK23, which restores activity to a hydE mutation that maps at minute 59 (Chaudhuri \& Krasna, 1987), did hybridize to band A. This clearly establishes that the mutation in strain AK 11 is not at minute 65 , a conclusion already suggested by experiments described above. pAK 11 hybridized to a band consisting of band $P(100 \mathrm{~kb}$, minutes 14-17) and band $R(95 \mathrm{~kb}$, minutes 25-27).

To determine whether the mutation was at minutes $14-17$ or $25-27$, the wild-type gene was isolated and mapped by $\mathrm{P} 1$ transduction. A P1 c100 lysate was prepared from an E. coli strain 
Table 2. Hydrogen uptake and formate phenotypes of P1 transductants

Recipient strain and phenotype

K12W6 (Tet ${ }^{\text {s }}$ Hup $^{+}$)

AK11 (Tet'sup ${ }^{-}$)

AK11 (Tet ${ }^{\mathrm{s}} \mathrm{Hup}^{-}$)

AK11 ( Tet $^{\mathrm{s}} \mathrm{Hup}^{-}$)

K12W6 (Tet ${ }^{\mathrm{S}} \mathrm{Hup}^{+}$)
Donor strain and phenotype

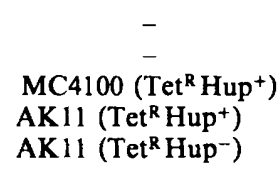

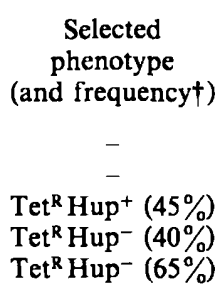

Activity* [nmol formate oxidized $\left.\min ^{-1}(\mathrm{mg} \text { protein })^{-1}\right]$

$\begin{array}{rrr}\text { FHL } & \text { FDH-2 } & \text { FDH-1 } \\ 55 & 87 & 67 \\ 0 & 8 & 3 \\ 98 & 107 & 55 \\ 0 & 0 & 2 \\ 0 & 0 & 0\end{array}$

* The values were obtained with intact cells and are the means of four separate determinations on each of two selected transductants of each phenotype. The maximum deviation from the mean was $\pm 15 \%$.

$\dagger$ The frequency of the selected phenotype was determined in 200-300 transductants in each case.

(MC4100) containing random $\mathrm{Tn} 10$ insertions $\left(\mathrm{Tet}^{\mathrm{R}} \mathrm{Hup}^{+}\right)$. Transposon $\mathrm{Tn} 10$ was introduced into strain AK11 ( Tet $^{\mathrm{S}} \mathrm{Hup}^{-}$) by generalized transduction with $\mathrm{P} 1 c 100$. Tet $^{\mathrm{R}}$ transductants were plated and screened for the $\mathrm{Hup}^{+}$phenotype. Of 200 transductants screened, $9 \%$ were $\mathrm{Hup}^{+}$. Lysates were prepared from these AK 11 ( Tet $^{\mathrm{R}} \mathrm{Hup}^{+}$) transductants by infection with P1 c100. These lysates, which contained the wild-type gene not expressed in strain AK11, were used to transduce a trpE mutant (minute 27.5) and a galK mutant (minute 16.7) to $\mathrm{Tet}^{\mathrm{R}} \mathrm{Trp}^{+}$and $\mathrm{Tet}^{\mathrm{R}} \mathrm{Gal}^{+}$, respectively. Of 200 transductants from the $\operatorname{trp} E$ mutant, all were $\mathrm{Tet}^{\mathrm{R}} \mathrm{Trp}^{-}$, establishing that the mutation in strain AK11 is not near minute 27. Transduction of the galK mutant gave $\mathrm{Tet}^{\mathrm{R}}$ transductants which were also $\mathrm{Gal}^{+}(45 \%$ of 200 transductants), showing that the AK 11 mutation is near minute 17 on the $E$. coli genome map.

None of the reported hydrogenase-related or formate-related genes map near minute 17. frdA, B, C and $D$, genes involved with fumarate reductase, map at minute 94.4 (Cole et al., 1985). The $f n r$ gene, which pleiotropically regulates hydrogenase synthesis, maps near minute 29 (Ingledew \& Poole, 1984; Tait, 1982) and mutations in this gene lead to complete loss of hydrogenase activity. Various formate dehydrogenase genes map at minutes 38, 80, 82, 87 and 92.4 (Ingledew \& Poole, 1984; Tait, 1982). The succinate dehydrogenase gene maps at minute 16.7 and is induced aerobically and repressed anaerobically (Ingledew \& Poole, 1984). Strains AK 11 and AK22 have the normal succinate-positive phenotype. We propose that the hup gene at minute 65 be designated as hupA and the hup gene at minute 17 as hupB.

With the hup mutation in strain AK11 mapped, it was necessary to establish whether the formate-related mutation was due to the same mutation or to a second unrelated mutation. This was accomplished by a series of P1 transductions and analysis of the transductants for both the hydrogen uptake and the formate-related phenotypes. The results are presented in Table 2. Transduction of strain AK11 $\left(\mathrm{Tet}^{\mathrm{S}} \mathrm{Hup}^{-}\right)$by a P1 lysate prepared from a $\mathrm{Tet}^{\mathrm{R}} \mathrm{Hup}^{+}$wild-type donor yielded strain AK 11 with a Tet $^{R}$ Hup $^{+}$phenotype (described above). These transductants all had high levels of the three formate-related activities (Table 2), suggesting that the hydrogen uptake and formate mutations in strain AK 11 may be due either to the same mutation or to two very close mutations. Strain $\mathrm{AK} 22\left(\mathrm{Tet}^{\mathrm{S}} \mathrm{Hup}^{-}\right)$was also transduced to the $\mathrm{Tet}^{\mathrm{R}} \mathrm{Hup}^{+}$phenotype and all transductants had recovered the formate-related activities along with the hydrogen uptake activities. Strains AK11 and AK22 have very similar properties although they were isolated by different mutagenic procedures (AK 11 by ultraviolet and AK 22 by nitrosoguanidine mutagenesis). The restoration of both hydrogen uptake and formate phenotypes in both strains by transduction from a wild-type donor suggests that there is a single very similar mutation in both strains rather than multiple mutations.

This was further confirmed by transferring the hup mutation to the wild-type parent K12W6 (Table 2). First the Tet $^{R}$ marker was introduced next to the hup mutation in strain AK 11 by P1 transduction of strain AK11 (Tet ${ }^{\mathrm{S}} \mathrm{Hup}^{-}$) with DNA from strain AK11 $\left(\mathrm{Tet}^{\mathrm{R}} \mathrm{Hup}^{+}\right.$) and selection of transductants with the $\mathrm{Tet}^{\mathrm{R}} \mathrm{Hup}^{-}$phenotype. As expected, the transductants lacked both hydrogen uptake and formate activities (Table 2). This strain was then used as donor to 
Table 3. Reduction of methyl viologen by $\mathrm{H}_{2}$ in strain $\mathrm{AK} 11$

$\begin{array}{llccc}\text { Strain } & \text { Plasmid } & \begin{array}{c}\text { Intact } \\ \text { cells }\end{array} & \begin{array}{c}\text { Membrane } \\ \text { vesicles }\end{array} & \begin{array}{c}\text { Solubilized } \\ \text { membranes }\end{array} \\ \text { K12W6 } & \text { None } & 6 & 6 & 17 \\ \text { AK11 } & \text { None } & 2 & 17 & 49 \\ \text { AK11 } & \text { pAK11 } & 9 & 22 & 89 \\ \text { AK11 } & \text { pAK11B } & 8 & \text { ND } & \text { ND } \\ \text { AK11 } & \text { pAK11P } & 7 & \text { ND } & \text { ND }\end{array}$

ND, Not determined.

- The values reported are the means of two separate determinations on each of three separate preparations. The maximum deviation from the mean was $\pm 10 \%$.

strain $\mathrm{K} 12 \mathrm{~W} 6$ and the $\mathrm{Tet}^{\mathrm{R}} \mathrm{Hup}^{-}$transductants were found to lack all the formate-related activities (Table 2).

It is thus clear that the mutation in strains $\mathrm{AK} 11$ and $\mathrm{AK} 22$ which leads to a Hup ${ }^{-}$phenotype also leads to loss of all formate-related activities. In spite of the single mutation (or perhaps two very close mutations), the cloned DNA fragments which restore the Hup ${ }^{+}$phenotype do not restore the formate phenotypes completely (see Table 1). Plasmid pAK11 hybridized to the chromosomal DNA of strains AK11 and AK22, showing that the mutant strains did not have large deletions in the genes involved.

\section{Hydrogen uptake activities in strain AKII}

Strains AK11 and AK22 clearly synthesize active hydrogenase when grown on glucose or complex medium. However, in whole cells the enzyme is active only for deuterium exchange, and not for reduction of viologen dyes by $\mathrm{H}_{2}$. The relationship between the loss of this catalytic activity and the failure to grow on fumarate plus $\mathrm{H}_{2}$ is not clear. Failure to grow on fumarate plus $\mathrm{H}_{2}$, in the presence of hydrogenase and fumarate reductase, could be due to a number of possible mutations. The mutation could be in a gene regulating synthesis of isoenzyme 2, the uptake hydrogenase (Ballantine \& Boxer, 1985; Sawers et al., 1985), with isoenzymes 1 and 3 (required for $\mathrm{H}_{2}$ evolution under different conditions of growth) being produced normally when cells are grown on glucose. The mutation could be in a gene coding for an electron-transport protein required for the $\mathrm{H}_{2}$-fumarate pathway but not for the glycerol-fumarate pathway, with all hydrogenase isoenzymes being synthesized normally. Alternatively, the $\mathrm{H}_{2}$-fumarate electron transport pathway may be normal, the mutation being in a gene coding for a protein product required for energy production during electron transport in the $\mathrm{H}_{2}$-fumarate pathway.

The different hydrogenase activities of strain AK11 as well as the isoenzyme profile were therefore examined. The first question to be addressed is why the active hydrogenase isoenzymes in this strain grown on glucose or complex medium do not catalyse reduction of methyl viologen by $\mathrm{H}_{2}$. Is this an inherent property of these isoenzymes or is it only manifested in intact cells? Membrane vesicles and solubilized membranes were prepared from the strains of interest and tested for reduction of methyl viologen. The membrane vesicles and solubilized membranes prepared from cells of strain AK11 (cells did not reduce methyl viologen by $\mathrm{H}_{2}$ ) reduced methyl viologen quite well, demonstrating that the hydrogenase isoenzymes released from the intact cell are fully capable of reducing methyl viologen. This is similar to the finding of Glick et al. (1980) with a different mutant strain; however, the latter strain grew on fumarate plus $\mathrm{H}_{2}$ (tested in this laboratory) and is different from strain AK11.

Reduction of methyl viologen by $\mathrm{H}_{2}$, in the absence of small quantities of sodium dithionite, gave rates (even in active preparations) that were too low to give accurate quantitative data. By addition of small quantities of sodium dithionite to remove residual oxygen, quantitative data were obtained as shown in Table 3. The small activity in strain AK11 could be real or due to some changes caused in the cell wall or membrane by the dithionite. In all cases, the activity in 

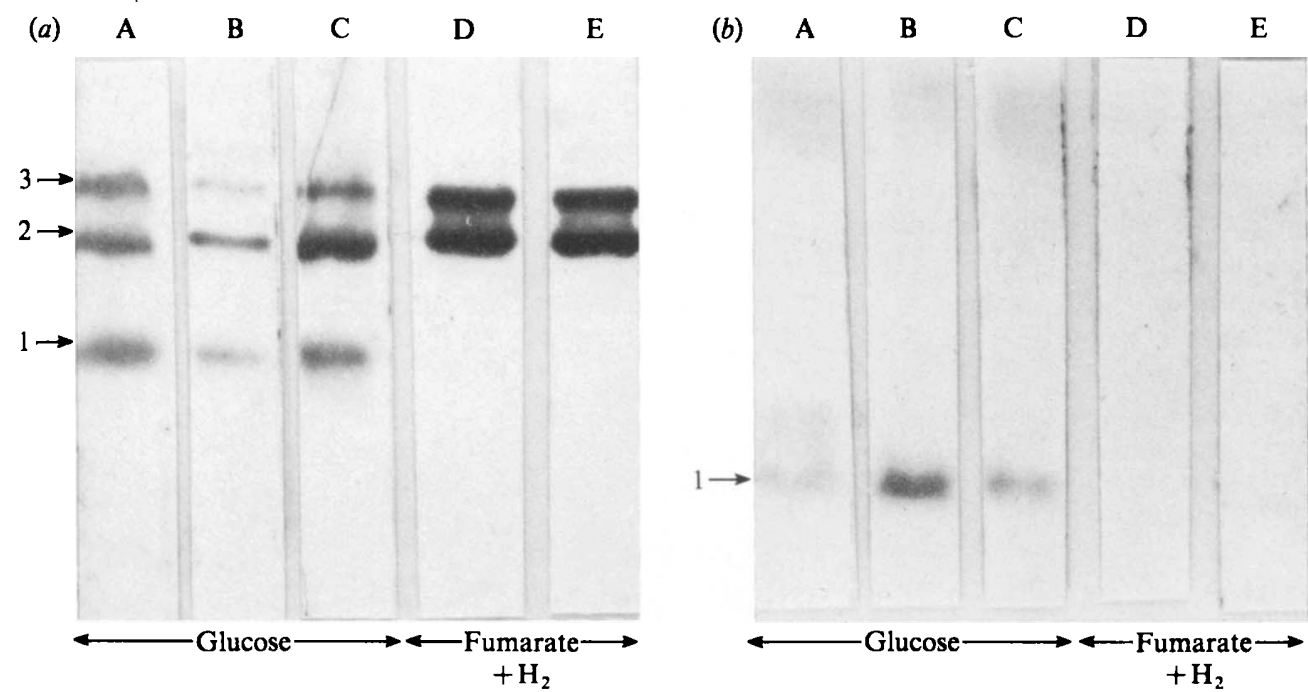

Fig. 3. Native gel electrophoresis of solubilized membranes. The gels were stained for hydrogenase activity by reduction of methyl viologen by $\mathrm{H}_{2}$ as outlined in Methods. Panel $(a)$ is from electrophoresis with the pH 8.0 system, panel $(b)$ with the pH 9.5 system. A, B and C, glucose-grown cells; D and E, cells grown on fumarate plus $\mathrm{H}_{2}$. A, K12W6; B, AK 11 ; C, AK 11 with plasmid pAK 11 ; D, K12W6; E, AK 11 with plasmid pAK 11 .

intact cells was restored by the cloned DNA fragments. The membrane vesicles and solubilized membranes from the mutant strain were fully capable of methyl viologen reduction and were even more active than those of the parental strain K12W6. Similar results to those reported in Table 3 were obtained with mutant strain AK22. The differences reported in Table 3 for reduction of methyl viologen by $\mathrm{H}_{2}$ in intact cells, membrane vesicles and solubilized membranes may reflect differences in the permeability of methyl viologen to hydrogenase in cells, vesicles and solubilized membranes. Jones \& Garland (1977) reported that oxidized or reduced methyl viologen, as well as dithionite anion, did not rapidly cross the $E$. coli cytoplasmic membrane, whereas reduced benzyl viologen did.

Since the solubilized membranes are capable of methyl viologen reduction, they could be analysed for the isoenzyme profile. The results are presented in Fig. 3 for strain AK11; identical results were obtained for strain AK22. The bands are referred to by the designation used by Ballantine \& Boxer (1985), band 1 representing isoenzyme 1 (required for $\mathrm{H}_{2}$ evolution) and bands 2 and 3 together representing isoenzyme 2 (required for $\mathrm{H}_{2}$ uptake). At $\mathrm{pH} 8 \cdot 0$, all three bands are observed in the parent strain K12W6 (lane A), the mutant strain AK11 (lane B), and strain AK 11 transformed by the plasmid pAK 11 (lane C), all grown on glucose. At pH 9.5, only band 1 is observed since isoenzyme 2 is irreversibly inactivated at high pH (Ballantine \& Boxer, 1985). In cells grown on fumarate plus $\mathrm{H}_{2}$ (lanes $\mathrm{D}$ and $\mathrm{E}$ ), only isoenzyme 2 is observed at pH 8.0 (bands 2 and 3), isoenzyme 1 content being negligible under these conditions (Sawers $e t$ al., 1985). At pH 9.5, no bands are observed (Fig. 3).

It is thus clear that strains AK 11 and AK22 contain the normal complement of hydrogenase isoenzymes 1 and 2, and the failure to grow on fumarate plus $\mathrm{H}_{2}$ cannot be ascribed to a lack of isoenzyme 2. To determine whether there is a deficiency in electron transport from $\mathbf{H}_{2}$ to fumarate in these strains, reduction of fumarate by $\mathrm{H}_{2}$ was measured in intact cells. Surprisingly, strains AK 11 and AK22 showed about half the activity of the parental strain [ $9 \mathrm{nmol} \mathrm{H}_{2}$ uptake $\mathrm{min}^{-1}$ (mg protein $)^{-1}$ in mutant strains versus 19 in parental strain]. The activity was increased in cells transformed by plasmid pAK 11 (to a specific activity of 15). Crude extracts of all cells could not reduce fumarate by $\mathrm{H}_{2}$, suggesting that disruption of the cells destroys the integrity of the electron-transport chain. Lee et al. (1985) reported that cells of class I hup mutant strains completely lack the ability to reduce fumarate by $\mathrm{H}_{2}$. This is yet another indication that the class I mutant strains are different from strains AK 11 and AK22. 
In spite of the ability of strains AK11 and AK22 to reduce fumarate by $\mathrm{H}_{2}$, they show no growth under these conditions. The lower levels of this activity (about half that of the parent or of cells transformed by plasmid pAK 11) may be insufficient to support growth. Alternatively, the electron-transport rate may be adequate but the mutation could be in a gene required to couple this electron-transport pathway to production of ATP required as an energy source for growth. The interesting observation is that this mutation also leads to the inability of intact cells to reduce methyl viologen by $\mathrm{H}_{2}$ although the hydrogenase isoenzymes 1 and 2 are all present and capable of carrying out this reaction. This mutation also leads to loss of formate-related activities.

This research was supported by the United States Department of Energy Grant no. DE-FG02-85ER13374. However, any opinions, findings, conclusions or recommendations expressed herein are those of the authors and do not necessarily reflect the view of the Department of Energy.

\section{REFERENCES}

Ballantine, S. P. \& Boxer, D. H. (1985). Nickelcontaining hydrogenase isoenzymes from anaerobically grown Escherichia coli K12. Journal of Bacteriology 163, 454-459.

Chaudhuri, A. \& Krasna, A. I. (1987). Isolation of genes required for hydrogenase synthesis in Escherichia coli. Journal of General Microbiology 133, 32893298.

Cole, S. T., Condon, C., Lemire, B. D. \& Weiner, J. H. (1985). Molecular biology, biochemistry and bioenergetics of fumarate reductase, a complex membrane-bound iron-sulfur flavoenzyme of $E s$ cherichia coli. Biochimica et biophysica acta 811, 381403.

Glick, B. R., Wang, P. Y., SchNeIdeR, H. \& MartiN, W. G. (1980). Identification and partial characterization of an Escherichia coli mutant with altered hydrogenase activity. Canadian Journal of Biochemistry 58, 361-367.

Ingledew, W. J. \& POOLE, R. K. (1984). The respiratory chain of Escherichia coli. Microbiological Reviews 48, 222-271.

JoNes, R. W. \& Garland, P. B. (1977). Sites and specificity of the reaction of bipyridylium compounds with anaerobic respiratory enzymes of Escherichia coli: effect of permeability barrier imposed by the cytoplasmic membrane. Biochemical Journal 164, 199-211.

KRASNA, A. I. (1978). Oxygen-stable hydrogenase and assay. Methods in Enzymology 53, 296-314.

KRASNA, A. I. (1980). Regulation of hydrogenase activity in enterobacteria. Journal of Bacteriology 144, 1094-1097.

KRASNA, A. I. (1984). Mutants of Escherichia coli with altered hydrogenase activity. Journal of General Microbiology 130, 779-787.

LAMBden, P. R. \& Guest, J. R. (1976). Mutants of Escherichia coli $\mathrm{K} 12$ unable to use fumarate as an anaerobic electron acceptor. Journal of General Microbiology 97, 145-160.

LeE, J. H., Patel, P., Sankar, P. \& Shanmugam, K. T. (1985). Isolation and characterization of mutant strains of Escherichia coli altered in $\mathrm{H}_{2}$ metabolism. Journal of Bacteriology 162, 344-352.

Macy, J., Kulla, H. \& GotrschalK, G. (1976). $\mathrm{H}_{2}-$ dependent growth of Escherichia coli on L-malate: succinate formation. Journal of Bacteriology 125, 423-428.

MAURER, H. R. (1971). Disc Electrophoresis and Related Techniques of Polyacrylamide Gel Electrophoresis, 2nd edn, p. 44. Berlin: Walter de Gruyter.

MILlER, J. H. (1972). Experiments in Molecular Genetics. Cold Spring Harbor, NY: Cold Spring Harbor Laboratory.

SANCAR, A., HaCk, A. M. \& Rupp, W. D. (1979). Simple method for identification of plasmid-coded proteins. Journal of Bacteriology 137, 692-693.

Sankar, P., LeE, J. H. \& Shanmugam, K. T. (1985). Cloning of hydrogenase genes and fine structure analysis of an operon essential for $\mathrm{H}_{2}$ metabolism in Escherichia coli. Journal of Bacteriology 162, 353-360.

Sawers, R. G., Ballantine, S. P. \& Boxer, D. H. (1985). Differential expression of hydrogenase isoenzymes in Escherichia coli K12: evidence for a third isoenzyme. Journal of Bacteriology 164, 1324-1331.

Smith, C. L., Econome, J. G., SchuTt, A., Klco, S. F. \& CANTOR, C. R. (1987). A physical map of the Escherichia coli K12 genome. Science 236, 14481453.

SPENCER, M. E. \& GuesT, J. R. (1973). Isolation and properties of fumarate reductase mutants of Escherichia coli. Journal of Bacteriology 114, 563-570.

TAIT, R. C. (1982). Hydrogenase genetics. Enzyme and Microbial Technology 4, 66-72.

WAUGH, R. \& BoXeR, D. H. (1986). Pleiotropic hydrogenase mutants of Escherichia coli K12: growth in the presence of nickel can restore hydrogenase activity. Biochimie 68, 157-166.

Yamamoto, I. \& Ishimoto, M. (1978). Hydrogendependent growth of Escherichia coli in anaerobic respiration and the presence of hydrogenase with different functions. Journal of Biochemistry 84, 673679. 